\title{
N-Terminal Modifications Improve the Receptor Affinity and Pharmacokinetics of Radiolabeled Peptidic Gastrin-Releasing Peptide Receptor Antagonists: Examples of ${ }^{68} \mathrm{Ga}$ - and ${ }^{64} \mathrm{Cu}$-Labeled Peptides for PET Imaging
}

\author{
Eleni Gourni ${ }^{1-3}$, Rosalba Mansi ${ }^{2,4}$, Mazen Jamous ${ }^{4}$, Beatrice Waser ${ }^{5}$, Christiane Smerling ${ }^{6}$, Antje Burian 6 , \\ Franz Buchegger ${ }^{7}$, Jean Claude Reubi ${ }^{5}$, and Helmut R. Maecke ${ }^{2}$ \\ ${ }^{1}$ German Cancer Consortium (DKTK), Heidelberg, Germany; ${ }^{2}$ Department of Nuclear Medicine, University Hospital Freiburg, \\ Freiburg, Germany; ${ }^{3}$ German Cancer Research Center (DKFZ), Heidelberg, Germany; ${ }^{4}$ Division of Radiological Chemistry, \\ University Hospital Basel, Basel, Switzerland; ${ }^{5}$ Department of Pathology, University Hospital Bern, Bern, Switzerland; ${ }^{6} 3 B$ \\ Pharmaceuticals, Berlin, Germany; and ${ }^{7}$ Department of Nuclear Medicine, Lausanne University Hospital, Lausanne, Switzerland
}

Gastrin-releasing peptide receptors (GRPrs) are overexpressed on a variety of human cancers, providing the opportunity for peptide receptor targeting via radiolabeled bombesin-based peptides. As part of our ongoing investigations into the development of improved GRPr antagonists, this study aimed at verifying whether and how Nterminal modulations improve the affinity and pharmacokinetics of radiolabeled GRPr antagonists. Methods: The potent GRPr antagonist MJ9, Pip-D-Phe-Gln-Trp-Ala-Val-Gly-His-Sta-Leu-NH $\mathrm{N}_{2}$ (Pip, 4-amino-1-carboxymethyl-piperidine), was conjugated to 1,4,7triazacyclononane, 1-glutaric acid-4,7 acetic acid (NODAGA), and 1,4,7-triazacyclononane-1,4,7-triacetic acid (NOTA) and radiolabeled with ${ }^{68} \mathrm{Ga}$ and ${ }^{64} \mathrm{Cu}$. The GRPr affinity of the corresponding metalloconjugates was determined using ${ }^{125} \mathrm{I}-\mathrm{Tyr}^{4}-\mathrm{BN}$ as a radioligand. The labeling efficiency of ${ }^{68} \mathrm{Ga}^{3+}$ was compared between NODAGA-MJ9 and NOTA-MJ9 in acetate buffer, at room temperature and at $95^{\circ} \mathrm{C}$. The ${ }^{68} \mathrm{Ga}$ and ${ }^{64} \mathrm{Cu}$ conjugates were further evaluated in vivo in PC3 tumor xenografts by biodistribution and PET imaging studies. Results: The half maximum inhibitory concentrations of all the metalloconjugates are in the high picomolar-low nanomolar range, and these are the most affine-radiolabeled GRPr antagonists we have studied so far in our laboratory. NODAGA-MJ9 incorporates ${ }^{68} \mathrm{Ga}^{3+}$ nearly quantitatively $(>98 \%)$ at room temperature within $10 \mathrm{~min}$ and at much lower peptide concentrations $\left(1.4 \times 10^{-6} \mathrm{M}\right)$ than NOTA-MJ9, for which the labeling yield was approximately $45 \%$ under the same conditions and increased to $75 \%$ at $95^{\circ} \mathrm{C}$ for $5 \mathrm{~min}$. Biodistribution studies showed high and specific tumor uptake, with a maximum of $23.3 \pm 2.0$ percentage injected activity per gram of tissue $(\% \mathrm{IA} / \mathrm{g})$ for ${ }^{68} \mathrm{Ga}-\mathrm{NOTA}-\mathrm{MJ} 9$ and $16.7 \pm 2.0 \% \mathrm{IA} / \mathrm{g}$ for ${ }^{68} \mathrm{Ga}-N O D A G A-M J 9$ at $1 \mathrm{~h}$ after injection. The acquisition of PET images with the ${ }^{64} \mathrm{Cu}-\mathrm{MJ} 9$ conjugates at later time points clearly showed the efficient clearance of the accumulated activity from the background already at $4 \mathrm{~h}$ after injection, whereas tumor uptake still remained high. The high pancreas uptake for all radiotracers at $1 \mathrm{~h}$ after injection was rapidly washed out, resulting in an increased tumor-to-pancreas ratio at later time points. Conclusion: We have developed 2 GRPr antagonistic radioligands, which are improved

Received Apr. 4, 2014; revision accepted Jul. 17, 2014.

For correspondence or reprints contact: Helmut Maecke, University Hospital Freiburg, Department of Nuclear Medicine, Hugstetter Strasse 55, 79106 Freiburg, Germany.

E-mail: helmut.maecke@uniklinik-freiburg.de

Published online Aug. 21, 2014.

COPYRIGHT (C) 2014 by the Society of Nuclear Medicine and Molecular Imaging, Inc. in terms of binding affinity and overall biodistribution profile. Their promising in vivo pharmacokinetic performance may contribute to the improvement of the diagnostic imaging of tumors overexpressing GRPr.

Key Words: gastrin-releasing peptide receptor antagonists; ${ }^{68} \mathrm{Ga}$; ${ }^{64} \mathrm{Cu}$; PET imaging

J Nucl Med 2014; 55:1719-1725

DOI: 10.2967/jnumed.114.141242

$\mathbf{T}$ he identification of tumors at an early stage has been a big challenge for oncologists. The ability to detect primary cancers is of major importance, and early diagnosis has made a significant contribution in reducing the number of deaths. The increasing evidence of peptide receptor overexpression in various tumors has generated interest in the development of radiolabeled peptides for their targeting either for radiodiagnostic or for targeted radiotherapeutic applications $(1,2)$. The gastrin-releasing peptide receptor (GRPr) is a representative example of this approach because this bombesin receptor family subtype is selectively overexpressed in human cancers including prostate, breast, and small cell lung $(2,3)$.

So far, many bombesin-based agonists have been developed and evaluated in preclinical and clinical studies, with the drawback of causing side effects after their administration to patients (4). The mitogenic properties of GRPr agonists are also a major concern that needs to be considered (5). Our recent experience with radiolabeled somatostatin receptor antagonists showing that they recognize more binding sites than agonists and therefore have higher tumor uptake in animals (6) prompted us to initiate a research project aiming at developing antagonistic GRPr radioligands to be used for clinical translation (7-11). Because the evaluation of the first GRPr antagonist in our laboratory, DO3A- $\mathrm{CH}_{2} \mathrm{CO}-\mathrm{Gly}-4-$ aminobenzoyl-D-Phe-Gln-Trp-Ala-Val-Gly-His-Sta-Leu- $\mathrm{NH}_{2}$ (RM1), labeled with ${ }^{111} \mathrm{In}$ and ${ }^{68} \mathrm{Ga}$, was superior to the most potent agonist ${ }^{111} \mathrm{In}-\mathrm{DO} 3 \mathrm{~A}-\mathrm{CH}_{2} \mathrm{CO}-\mathrm{Gly}$-4-aminobenzoyl-Gln-TrpAla-Val-Gly-His-Leu-Met- $\mathrm{NH}_{2}\left({ }^{111} \mathrm{In}-\mathrm{AMBA}\right)$ in terms of tumor uptake and tumor-to-normal tissue ratios (8), we continued with 
the development and evaluation of a series of GRPr antagonists useful for imaging and potentially targeted radionuclide therapy. The fact that RM1 showed a distinct advantage over the potent agonist AMBA prompted us to continue with the development of statine-based GRPr antagonists H-D-Phe-Gln-Trp-Ala-Val-Gly-HisSta-Leu- $\mathrm{NH}_{2}$ (12), aiming at improving their pharmacokinetic performance. Thus, a variety of chelators and spacers were introduced $\mathrm{N}$-terminally, and the derived conjugates were labeled with a series of radionuclides $(8-10)$.

Herein, the antagonistic peptide was functionalized with the chelators 1,4,7-triazacyclononane-1,4,7-triacetic acid (NOTA) and 1,4,7-triazacyclononane, 1-glutaric acid-4,7 acetic acid (NODAGA) via the spacer 4-amino-1-carboxymethyl-piperidine (Pip) to obtain NOTA- and NODAGA-MJ9, respectively (Fig. 1), and radiolabeled with ${ }^{68} \mathrm{Ga}$ and ${ }^{64} \mathrm{Cu}$. One of our goals was to study the influence of the extra negative charge from the third carboxymethyl arm of NODAGA, compared with NOTA-monoamide, on the labeling efficiency. Additionally, we investigated how the $\mathrm{N}$-terminal charge influences receptor binding affinity. All the ${ }^{\text {nat }} \mathrm{Ga}$ and ${ }^{\text {nat }} \mathrm{Cu}$ metalloconjugates showed high GRPr affinity with half maximum inhibitory concentration $\left(\mathrm{IC}_{50}\right)$ values in the high picomolar-low nanomolar range, determined on GRPr-expressing cryostat sections of prostate carcinoma. We also describe the evaluation of the ${ }^{68} \mathrm{Ga}-$ and ${ }^{64} \mathrm{Cu}$-labeled conjugates with a particular focus on ${ }^{68} \mathrm{Ga}$ labeling, biodistribution, and PET imaging in PC3 xenografts. Within the bombesin receptor family, the PC3 cells overexpress only GRPr.

\section{MATERIALS AND METHODS}

The supplier information for all reagents and details of instruments used are provided in the supplemental data (available at http://jnm. snmjournals.org).

\section{Synthesis of Chelator-Peptide Conjugates}

The peptide-chelator conjugates were synthesized manually using standard Fmoc chemistry (13) and Rink amide 4-methylbenzhydrylamine resin. The spacer and protected chelators were consecutively coupled to the peptide using 1-[Bis(dimethylamino)methylene]$1 \mathrm{H}-1,2,3$-triazolo[4,5-b]pyridinium 3-oxid hexafluorophosphate as an activating agent. The cleavage of the peptides and the simultaneous

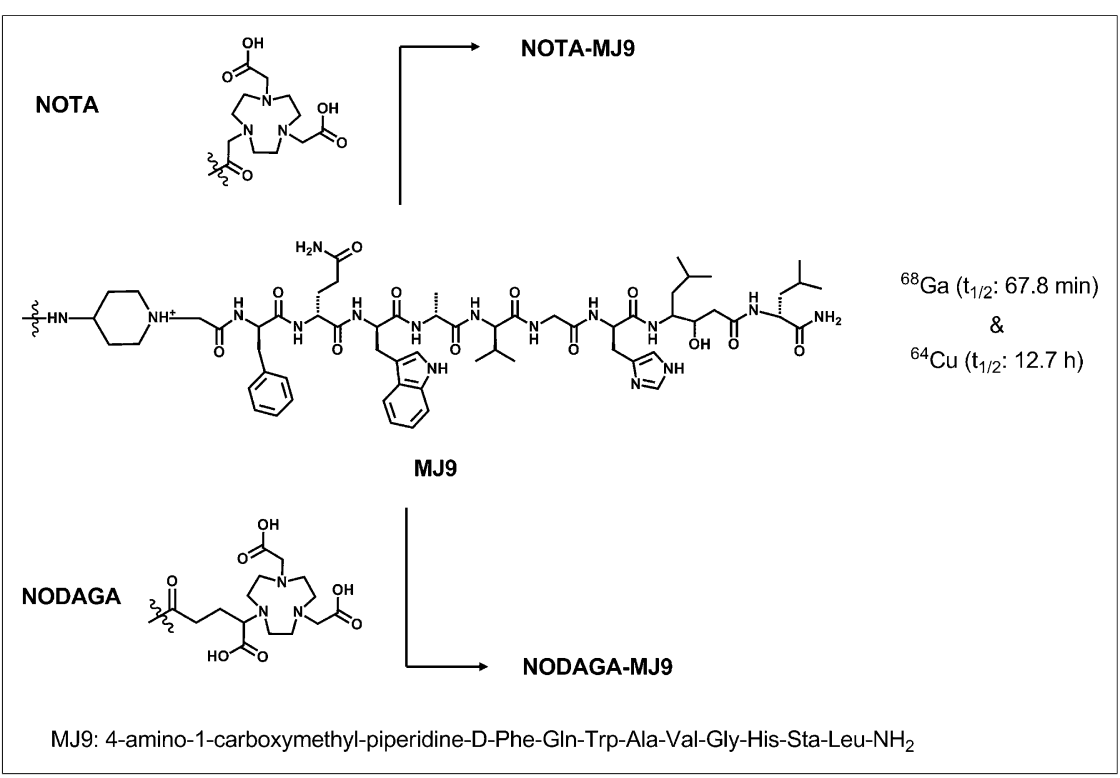

FIGURE 1. Schematic structures of NOTA-MJ9 and NODAGA-MJ9. $t_{1 / 2}=$ half-life. deprotection of the side chain-protecting groups were performed using trifluoroacetic acid/thioanisole/triisopropylsilane/ $\mathrm{H}_{2} \mathrm{O}(95 / 2 / 2 / 1)$. The crude conjugates were further purified by semipreparative highperformance liquid chromatography.

\section{Radiochemistry and Preparation of nat $\mathrm{Ga}$ and nat $\mathrm{Cu}$ Metallopeptides}

The radioligands were prepared as described in detail in the supplemental data. ${ }^{68} \mathrm{Ga}$ conjugates were prepared within $10 \mathrm{~min}$ either at room temperature or at $95^{\circ} \mathrm{C}$ starting with 5-20 $\mu \mathrm{g}(\sim 3-12 \mathrm{nmol})$ of the conjugates, using the Modular-Lab PharmTracer module (Eckert \& Ziegler). The ${ }^{64} \mathrm{Cu}$-labeled radioligands were prepared by dissolving $10 \mu \mathrm{g}(\sim 5 \mathrm{nmol})$ of each peptide in $250 \mu \mathrm{L}$ of ammonium acetate buffer $(0.1 \mathrm{~mol} / \mathrm{L}, \mathrm{pH} 8.0)$, followed by incubation with ${ }^{64} \mathrm{CuCl}_{2}(180-$ $200 \mathrm{MBq}$ ) for $30 \mathrm{~min}$ at $95^{\circ} \mathrm{C}$, and were used without any further purification step.

The ${ }^{\text {nat }} \mathrm{Ga}$ and ${ }^{\text {nat }} \mathrm{Cu}$ metallopeptides were prepared using a 2.5-fold excess of ${ }^{\text {nat }} \mathrm{Ga}\left(\mathrm{NO}_{3}\right)_{3} \times \mathrm{H}_{2} \mathrm{O}, 0.3 \mathrm{M},{ }^{\text {nat }} \mathrm{CuCl}_{2} \times 2 \mathrm{H}_{2} \mathrm{O}, 0.3 \mathrm{M}$, at the same conditions used for the labeling (supplemental data).

\section{Determination of Binding Affinity and Calcium Flux Assay}

The binding affinity profiles ( $\mathrm{IC}_{50}$ values) of ${ }^{\text {nat }} \mathrm{Ga}$-NOTA-MJ9,

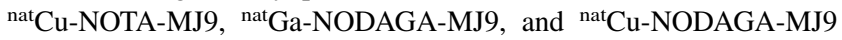
and native $\mathrm{BN}$ were determined by in vitro GRPr autoradiography on cryostat sections of well-characterized prostate carcinomas as described previously (14). The radioligand used was ${ }^{125} \mathrm{I}_{-} \mathrm{Tyr}^{4}{ }_{-}$ bombesin, known to preferentially label GRPr.

Calcium flux was determined using a Flexstation II 384 from Molecular Devices. PC3 cells were seeded at a density of 25,000 cells per well in 96-well plates and incubated with $100 \mu \mathrm{L}$ of $\mathrm{Ca} 5$ dye R8186 solution including probenecid $(5 \mathrm{mmol} / \mathrm{L})$ diluted with washing buffer. For antagonist assay, cells were preincubated with serial dilutions of the antagonists, followed by the concentration giving $80 \%$ of the maximal $\mathrm{Ca}^{2+}$ response of $\mathrm{Tyr}^{4}-\mathrm{BN}$. The change of the fluorescent signal was recorded continually for $90 \mathrm{~s}$ at $538 \mathrm{~nm}$.

\section{Cell Line and Animal Model}

The PC3 human prostate cancer cell line, which is known to overexpress GRPr, was cultured at $37^{\circ} \mathrm{C}$ and $5 \% \mathrm{CO}_{2}$ in Dulbecco modified Eagle medium containing $10 \%$ fetal bovine serum, penicillin (100 U/mL), and streptomycin $(100 \mu \mathrm{g} / \mathrm{mL})$.

Female athymic BALB/C nude mice (age, 4-6 wk; weight, 17-20 g) were purchased from Janvier. For implantation, the tumor cells were harvested by trypsinization, and $5 \times 10^{6}$ cells in $100 \mu \mathrm{L}$ of phosphate-buffered saline were inoculated subcutaneously into the right shoulder of the mice. After an average of $3 \mathrm{wk}$, tumor size reached 200-300 mg and the animals were used for biodistribution and PET imaging studies. All animal experiments were approved by local authorities and were in compliance with the institutional guidelines.

\section{Biodistribution and Small-Animal PET Studies in PC3 Xenografts}

Ten picomoles and $0.3-0.4 \mathrm{MBq}$ of ${ }^{68} \mathrm{Ga}$ NOTA-MJ9 or ${ }^{68}$ Ga-NODAGA-MJ9 in 100 $\mu \mathrm{L}$ of $\mathrm{NaCl} 0.9 \%$ were injected intravenously into the tail vein of PC3 mice. Animals were sacrificed by isoflurane anesthesia at 1 and $2 \mathrm{~h}$ after injection of the ${ }^{68} \mathrm{Ga}$-labeled vectors (supplemental data). 
TABLE 1

Analytic and Affinity Data of Metallated Peptides

\begin{tabular}{|c|c|c|c|c|c|}
\hline Compound & $\begin{array}{l}\text { Calculated monoisotopic } \\
\text { mass: } \mathrm{m} / \mathrm{z}([\mathrm{M}+\mathrm{H}]+)\end{array}$ & $\begin{array}{c}\text { Electrospray ionization mass } \\
\text { spectrometry (ESI-MS): } \mathrm{m} / \mathrm{z}([\mathrm{M}+\mathrm{H}]+)\end{array}$ & $\begin{array}{c}\mathrm{IC}_{50} \\
(\mathrm{nmol} / \mathrm{L})\end{array}$ & $\mathrm{Ca}^{2+}$ flux & $\begin{array}{c}\text { Charge at the } \\
\mathrm{N} \text { terminus }\end{array}$ \\
\hline Native BN & & & $3.4 \pm 1.1$ & & \\
\hline natGa-NOTA-MJ9 & $1,606.569$ & $1,606.750$ & $0.5 \pm 0.1$ & No $\mathrm{Ca}^{2+}$ release & +1 \\
\hline natGa-NODAGA-MJ9 & $1,678.590$ & $1,678.773$ & $2.1 \pm 0.3$ & Antagonist & 0 \\
\hline${ }^{\text {nat }} \mathrm{Cu}-\mathrm{NOTA}-\mathrm{MJ9}$ & $1,600.392$ & $1,599.760$ & $1.0 \pm 0.1$ & & 0 \\
\hline${ }^{\text {nat }} \mathrm{Cu}-\mathrm{NODAGA-MJ9}$ & $1,672.413$ & $1,671.784$ & $5.3 \pm 2.5$ & & -1 \\
\hline
\end{tabular}

PET images were obtained on injection of 100 pmol of the radioligands $\left({ }^{68} \mathrm{Ga}-\mathrm{NOTA}-\mathrm{MJ} 9\right.$ or ${ }^{68} \mathrm{Ga}$-NODAGA-MJ9, 1.6-1.8 $\mathrm{MBq} / 100 \mu \mathrm{L} ;{ }^{64} \mathrm{Cu}$-NOTA-MJ9 or ${ }^{64} \mathrm{Cu}-\mathrm{NODAGA-MJ9,} 2.5-3.0$ $\mathrm{MBq} / 100 \mu \mathrm{L})$. For the ${ }^{68} \mathrm{Ga}$-labeled compounds, static images were acquired for a time period of $30 \mathrm{~min}$ at $1 \mathrm{~h}$ after injection and for the ${ }^{64} \mathrm{Cu}$ radiotracers at 1,4 , and $24 \mathrm{~h}$ after injection (supplemental data).

\section{RESULTS}

\section{Chemistry and Radiochemistry}

The synthesis yields of the peptide-chelator conjugates ranged from $30 \%$ to $40 \%$. The purity and identity of the peptides were greater than $95 \%$ as determined by high-performance liquid chromatography and mass spectroscopy (Table 1 ).

NODAGA-MJ9 incorporates ${ }^{68} \mathrm{Ga}$ nearly quantitatively $(>98 \%)$ at room temperature and at much lower peptide concentrations $\left(5 \mu \mathrm{g}\right.$ or $\left.1.4 \times 10^{-6} \mathrm{M}\right)$ than NOTA-MJ9, for which the labeling yield was approximately $45 \%$ under the same conditions and increased to $73 \%$ after heating for $5 \mathrm{~min}$ at $95^{\circ} \mathrm{C}$ (Fig. 2). NODAGA-MJ9 and NOTA-MJ9 were labeled with ${ }^{68} \mathrm{Ga}$, with a labeling yield greater than $98 \%$ and specific activities of approximately 130 and $60 \mathrm{GBq} / \mu \mathrm{mol}$, respectively. The labeling yields for ${ }^{64} \mathrm{Cu}$ conjugates were greater than $95 \%$ after heating for $30 \mathrm{~min}$ at $95^{\circ} \mathrm{C}$ at a specific activity of $30 \mathrm{GBq} / \mu \mathrm{mol}$.

\section{Binding Affinities and Calcium Flux Assay}

The binding of $\left[{ }^{125} \mathrm{I}_{-} \mathrm{Tyr}^{4}\right]-\mathrm{BN}$ to the GRPr measured on human tumors was inhibited by various concentrations of ${ }^{\text {nat }} \mathrm{Ga}-/{ }^{\text {nat }} \mathrm{Cu}-$ NOTA-MJ9 and NODAGA-MJ9, respectively, and the $\mathrm{IC}_{50}$ values were in the high picomolar-low nanomolar range (Table 1). The affinities are even improved for the metallated conjugates, compared with the native bombesin. A typical inhibition of $\left.{ }^{125}{ }^{12-T y r}{ }^{4}\right]-B N$ binding is shown in Figure 3.

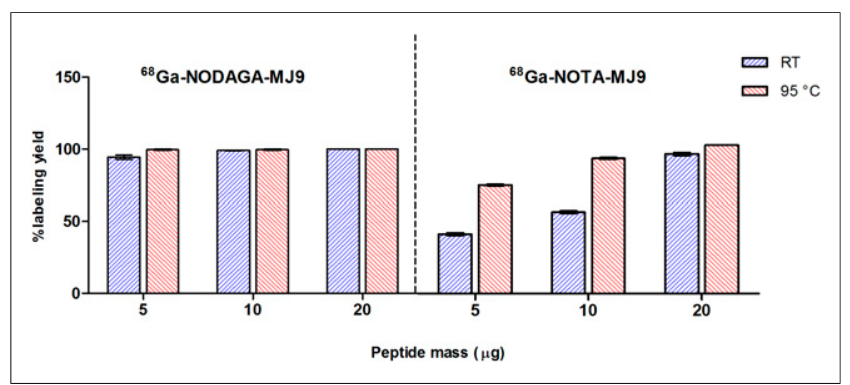

FIGURE 2. Peptide mass dependence of radiolabeling yields of NODAGA-MJ9 and NOTA-MJ9 after their labeling in $2 \mathrm{~mL}$ of sodium acetate buffer $(0.2 \mathrm{M}, \mathrm{pH} 4.0)$ with approximately $400 \mathrm{MBq}$ of ${ }^{68} \mathrm{Ga}$ for $10 \mathrm{~min}$ at room temperature (RT) or at $95^{\circ} \mathrm{C}$.
Calcium flux studies showed that ${ }^{\text {nat }}$ Ga-NOTA-MJ9 behaves as an antagonist as it is not inducing any calcium flux in PC3 cells in culture.

\section{Biodistribution in PC3 Xenografts}

The biodistribution data are summarized in Table 2 . Both ${ }^{68} \mathrm{Ga}-$ labeled tracers showed fast blood clearance, with approximately 0.3 percentage injected activity per gram of tissue $(\% \mathrm{IA} / \mathrm{g})$ left in blood at $2 \mathrm{~h}$ after injection. High tumor uptake over the time was also observed and even at $2 \mathrm{~h}$ after injection was approximately $20 \% \mathrm{IA} / \mathrm{g}$ for both ${ }^{68} \mathrm{Ga}$-labeled radiotracers. The uptake in the pancreas was about $65 \% \mathrm{IA} / \mathrm{g}$ for both radiotracers at $1 \mathrm{~h}$ after injection, which dropped to about $40 \% \mathrm{IA} / \mathrm{g}$ at $2 \mathrm{~h}$ after injection. GRPr binding specificity was demonstrated by more than $95 \%$ reduction of uptake in the tumor- and receptor-positive organs after coinjection of $20 \mathrm{nmol}$ of the respective ${ }^{\text {nat }}$ Me peptides.

\section{Small-Animal PET Studies}

Representative PET images obtained on injection of ${ }^{68} \mathrm{Ga}-$ NOTA-MJ9 and ${ }^{68}$ Ga-NODAGA-MJ9 in PC3 xenografts at $1 \mathrm{~h}$ after injection, which visualize the tumors well and represent the results of the biodistribution studies, are shown in Figure 4. Specific tumor uptake was visualized $1 \mathrm{~h}$ after the administration of both ${ }^{68} \mathrm{Ga}$-labeled MJ9 conjugates; the uptake in the abdomen is dominated by the pancreas and intestine, which were also blockable after the coinjection of $20 \mathrm{nmol}$ of the respective ${ }^{\text {nat }} \mathrm{Me}$ peptides.

The pharmacokinetics of ${ }^{64} \mathrm{Cu}-\mathrm{NOTA}-\mathrm{MJ} 9$ and ${ }^{64} \mathrm{Cu}-\mathrm{NODAGA}-\mathrm{MJ} 9$ were determined by small-animal PET (Figs. 5 and 6) at 1, 4, and $24 \mathrm{~h}$ in the same animals. Biodistribution was performed only at $24 \mathrm{~h}$ (Supplemental Table 1). Both radiotracers were specifically taken up by the GRPr-positive organs, such as the tumor and the pancreas, at early time points. The ${ }^{64} \mathrm{Cu}$ PET studies of both GRPr antagonists showed excellent pharmacokinetics, with only marginal uptake in nontumor tissue at 4 and $24 \mathrm{~h}$, respectively. Tumor uptake of ${ }^{64} \mathrm{Cu}-\mathrm{NOTA}-\mathrm{MJ} 9$ is higher than ${ }^{64} \mathrm{Cu}-\mathrm{NOGADA}-\mathrm{MJ} 9$, and ${ }^{64} \mathrm{Cu}-\mathrm{NOTA}-\mathrm{MJ} 9$ also shows longer retention. Both ${ }^{64} \mathrm{Cu}$-labeled conjugates showed low liver uptake.

\section{DISCUSSION}

The increasing evidence of G-protein-coupled receptor overexpression in various human tumors has generated interest in the development of radiolabeled peptides with the potential to be applied in peptide receptor-mediated radiodiagnosis or therapy $(1,15)$. One example of this approach is the GRPr, overexpressed in several human cancers $(2,3)$. Our aim was to develop antagonistic peptidebased radiotracers targeting the GRPr for clinical translation. Various radiolabeled GRPr agonists have been synthesized, evaluated, and applied in nuclear oncology (4,16-23). Innovative developments using agonists hybridized with other targeting units such as $\alpha_{v} \beta_{3}$ integrins or hypoxia-targeting agents such as 2-nitroimidazoles 


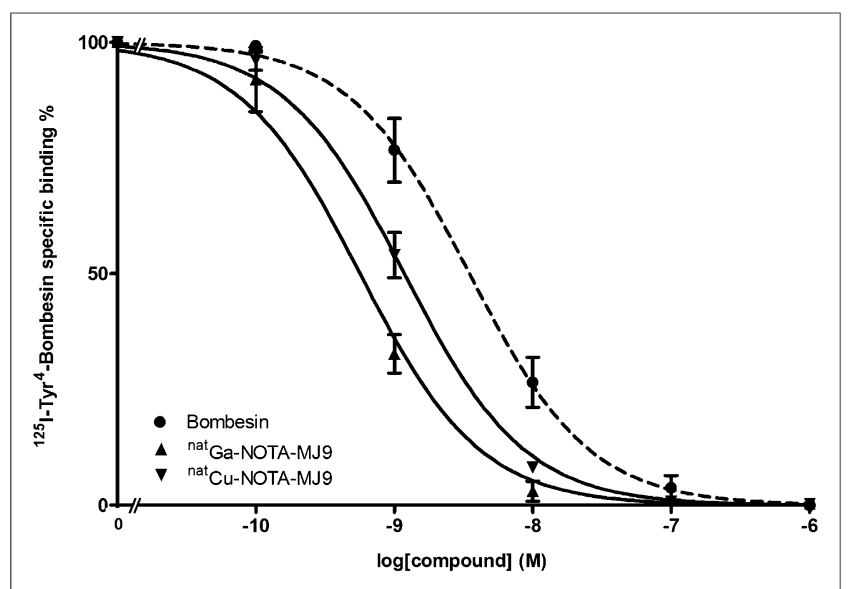

FIGURE 3. Displacement curves of [125I-Tyr $\left.{ }^{4}\right]$-bombesin by native bombesin, natGa-NOTA-MJ9, and natCu-NOTA-MJ9.

have been reported $(22,23)$, with the latter hybrids showing distinctly improved retention in tumor cells in vitro and in vivo. Durkan et al. (24) recently evaluated a ${ }^{64} \mathrm{Cu}$-labeled arginine-glycine-aspartate (RGD)-statine-based GRPr antagonist, [RGD-Glu- $\left[{ }^{64} \mathrm{Cu}-\mathrm{NO} 2 \mathrm{~A}\right]-$ 6-Ahx-RM2], which showed faster washout from the pancreas and longer retention in tumor tissue than the agonist [RGD-Glu$\left.\left[{ }^{64} \mathrm{Cu}-\mathrm{NO} 2 \mathrm{~A}\right]-6-\mathrm{Ahx}-\mathrm{BBN}\right]$ conjugate (25).

The successful pharmacokinetic performance of somatostatin-based antagonistic radiotracers preclinically $(6,26,27)$ and clinically $(28)$ led several research groups to develop GRPr antagonists, which indeed exhibit pharmacokinetics superior to agonists (7-10,29-32). Despite these promising data with the first antagonists, there is no consensus that antagonists are superior to agonists targeting the $\operatorname{GRPr}(33,34)$.

Among the several GRPr antagonists studied in our laboratory, the statine-based bombesin derivatives D-Phe-Gln-Trp-Ala-ValGly-His-Sta-Leu- $\mathrm{NH}_{2}$ (12) show excellent pharmacokinetic performance and were chosen as the peptide motif of the current study as well. The development of the potent GRPr antagonist ${ }^{68} \mathrm{Ga}-\mathrm{RM} 1$ showed preclinical performance superior to ${ }^{68} \mathrm{Ga}-$ AMBA (8). We further continued with the antagonist DOTA-4amino-1-carboxymethyl-piperidine-D-Phe-Gln-Trp-Ala-Val-Gly-HisSta-Leu- $\mathrm{NH}_{2}$ (RM2), indicating that ${ }^{111} \mathrm{In}-\mathrm{RM} 2$ and ${ }^{68} \mathrm{Ga}-\mathrm{RM} 2$ are good candidates for clinical SPECT and PET studies (9). The firstin-human study showed that the intravenous injection of ${ }^{68} \mathrm{Ga}-\mathrm{RM} 2$ is safe, but rapid metabolism is demonstrated (35). Nevertheless, clinical studies by us (G. Wieser, I. Popp, H.R. Maecke, T.P. Meyer, unpublished data, 2014) and others (36) confirmed the potency of ${ }^{68} \mathrm{Ga}-\mathrm{RM} 2$ for the detection of primary prostate cancer and recurrent disease. The high specificity of ${ }^{68} \mathrm{Ga}-\mathrm{RM} 2$ led to clear delineation of positive lymph nodes in patients with primary prostate cancer when other PET agents such as ${ }^{18} \mathrm{~F}$-choline were negative.

Throughout this study, our main goal was to investigate whether and how N-terminal modulations may improve the GRPr affinity and the pharmacokinetics of radiolabeled GRPr antagonists. The coupling of the positively charged piperidine-based spacer, the conjugation of NOTA or NODAGA, and the metallation with ${ }^{\text {nat }} \mathrm{Ga}^{\mathrm{III}}$ and ${ }^{\text {nat }} \mathrm{Cu}^{\mathrm{II}}$ do influence the GRPr binding affinity of the metalloconjugates. A side-by-side comparison of the binding affinities along with our previous findings, both with bombesin agonists (supplemental data), reveal that there is a correlation of improved affinity when the $\mathrm{N}$ terminus carries an overall positive

TABLE 2

Biodistribution Data of ${ }^{68} \mathrm{Ga}-\mathrm{NOTA}-\mathrm{MJ9}$ and ${ }^{68} \mathrm{Ga}-\mathrm{NODAGA}-\mathrm{MJ9}$ in PC3 Xenografts

\begin{tabular}{|c|c|c|c|c|c|c|}
\hline \multirow[b]{2}{*}{ Organ } & \multicolumn{3}{|c|}{${ }^{68} \mathrm{Ga}-N O T A-M J 9$} & \multicolumn{3}{|c|}{${ }^{68} \mathrm{Ga}-\mathrm{NODAGA-MJ9}$} \\
\hline & $1 \mathrm{~h}$ & 1-h blocked & $2 \mathrm{~h}$ & $1 \mathrm{~h}$ & 1-h blocked & $2 \mathrm{~h}$ \\
\hline Blood & $0.7 \pm 0.1$ & $0.3 \pm 0.1$ & $0.3 \pm 0.04$ & $0.9 \pm 0.1$ & $0.5 \pm 0.3$ & $0.3 \pm 0.02$ \\
\hline Heart & $0.1 \pm 0.07$ & $0.1 \pm 0.02$ & $0.14 \pm 0.12$ & $0.3 \pm 0.1$ & $0.2 \pm 0.1$ & $0.07 \pm 0.04$ \\
\hline Liver & $0.7 \pm 0.08$ & $0.6 \pm 0.2$ & $0.5 \pm 0.05$ & $1.1 \pm 0.1$ & $0.5 \pm 0.07$ & $0.6 \pm 0.1$ \\
\hline Spleen & $0.4 \pm 0.04$ & $0.2 \pm 0.04$ & $0.3 \pm 0.00$ & $1.0 \pm 0.2$ & $0.3 \pm 0.03$ & $0.5 \pm 0.1$ \\
\hline Lung & $0.6 \pm 0.1$ & $0.4 \pm 0.06$ & $0.4 \pm 0.02$ & $1.0 \pm 0.03$ & $0.7 \pm 0.3$ & $0.3 \pm 0.03$ \\
\hline Kidney & $3.7 \pm 0.6$ & $3.8 \pm 0.7$ & $3.2 \pm 0.2$ & $3.6 \pm 0.4$ & $3.5 \pm 0.2$ & $3.0 \pm 0.3$ \\
\hline Stomach & $5.8 \pm 0.4$ & $0.2 \pm 0.07$ & $5.1 \pm 0.8$ & $5.0 \pm 0.4$ & $0.3 \pm 0.2$ & $5.2 \pm 0.2$ \\
\hline Intestine & $7.6 \pm 0.4$ & $0.4 \pm 0.2$ & $6.1 \pm 1.1$ & $9.1 \pm 0.3$ & $0.4 \pm 0.2$ & $4.5 \pm 0.2$ \\
\hline Adrenal & $6.5 \pm 3.6$ & $0.8 \pm 0.3$ & $6.6 \pm 1.5$ & $9.2 \pm 1.7$ & $0.3 \pm 0.2$ & $5.6 \pm 0.7$ \\
\hline Pancreas & $68.6 \pm 6.6$ & $0.3 \pm 0.06$ & $41.8 \pm 1.5$ & $64 \pm 3.0$ & $0.2 \pm 0.04$ & $41.4 \pm 7.0$ \\
\hline Muscle & $0.3 \pm 0.2$ & $0.08 \pm 0.06$ & $0.3 \pm 0.1$ & $0.4 \pm 0.2$ & $0.1 \pm 0.04$ & $0.2 \pm 0.03$ \\
\hline Bone & $0.6 \pm 0.5$ & $0.4 \pm 0.2$ & $1.0 \pm 0.3$ & $1.4 \pm 0.5$ & $0.2 \pm 0.1$ & $0.8 \pm 0.01$ \\
\hline PC3 tumor & $23.3 \pm 2.0$ & $0.8 \pm 0.2$ & $19.6 \pm 0.9$ & $16.7 \pm 2.0$ & $0.6 \pm 0.3$ & $20.4 \pm 1.2$ \\
\hline Tumor-to-blood & $35 \pm 6.9$ & & $61 \pm 10.8$ & $19 \pm 1.6$ & & $64 \pm 10$ \\
\hline Tumor-to-liver & $32 \pm 2.8$ & & $36 \pm 5.0$ & $15 \pm 0.6$ & & $37 \pm 4.4$ \\
\hline Tumor-to-kidney & $6.5 \pm 0.8$ & & $6.3 \pm 0.7$ & $4.7 \pm 0.1$ & & $6.7 \pm 0.2$ \\
\hline Tumor-to-pancreas & $0.3 \pm 0.01$ & & $0.5 \pm 0.01$ & $0.3 \pm 0.02$ & & $0.5 \pm 0.06$ \\
\hline Tumor-to-muscle & $90 \pm 49$ & & $85 \pm 41$ & $46 \pm 23$ & & $123 \pm 22$ \\
\hline
\end{tabular}

Data are expressed in \% IA/g and are presented as mean \pm SD $(n=3-4)$. 


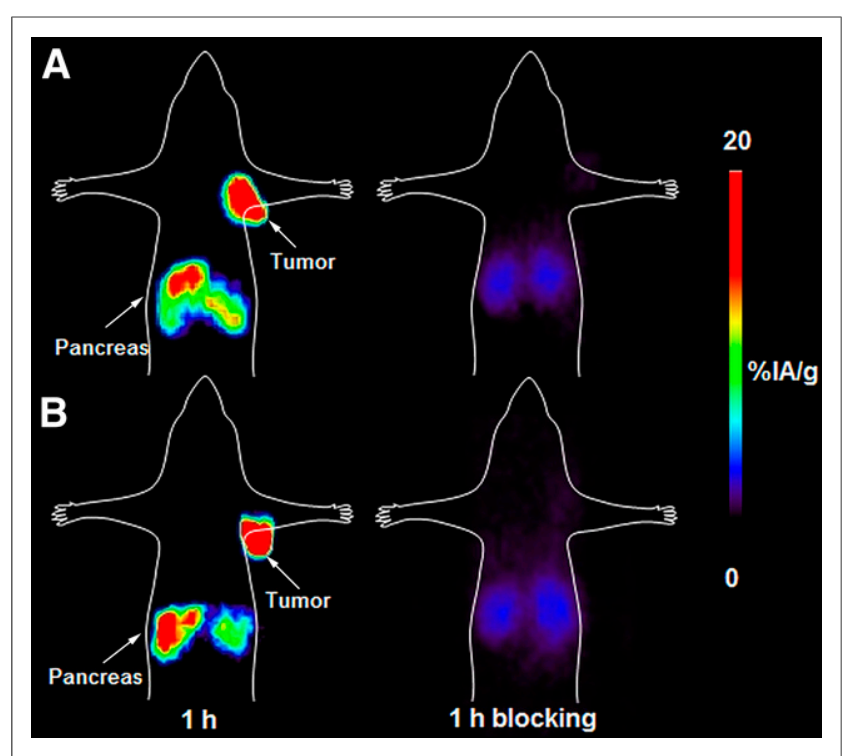

FIGURE 4. PET imaging of $P C 3$ tumor-bearing mice on injection of ${ }^{68} \mathrm{Ga}-N O D A G A-M J 9$ and ${ }^{68} \mathrm{Ga}-N O T A-M J 9$ at $1 \mathrm{~h}$ after injection along with blocking studies. Tumor and pancreas are indicated with arrows.

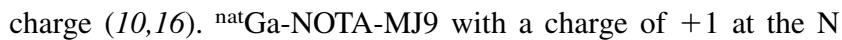
terminus has the highest affinity, followed by ${ }^{\text {nat }} \mathrm{Cu}-\mathrm{NOTA}-\mathrm{MJ} 9$ and ${ }^{n a t}$ Ga-NODAGA-MJ9, which are neutral, whereas ${ }^{\text {nat }} \mathrm{Cu}-$ NODAGA-MJ9 (negatively charged) has a 10-fold-lower affinity

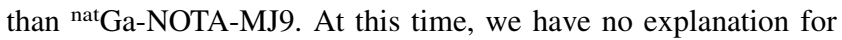
this improvement. Data from Lears et al., with the sarcophaginetype chelator coupled to $\mathrm{BN}(7-14)$ with different spacers and labeled with ${ }^{64} \mathrm{Cu}$, point in the same direction. The affinity of their positively charged peptides is high, and tumor and pancreas uptake are among the highest reported in the literature for GRPr agonists studied in PC3 xenografts (37). To confirm that the N-terminal modulations did not change the antagonist features, we performed a $\mathrm{Ca}^{2+}$ flux assay, which showed no $\mathrm{Ca}^{2+}$ release when PC3 cells

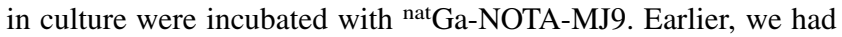
shown that an immunofluorescence assay showed no receptor internalization of the DOTA-PEG 4 -modified peptide (10).

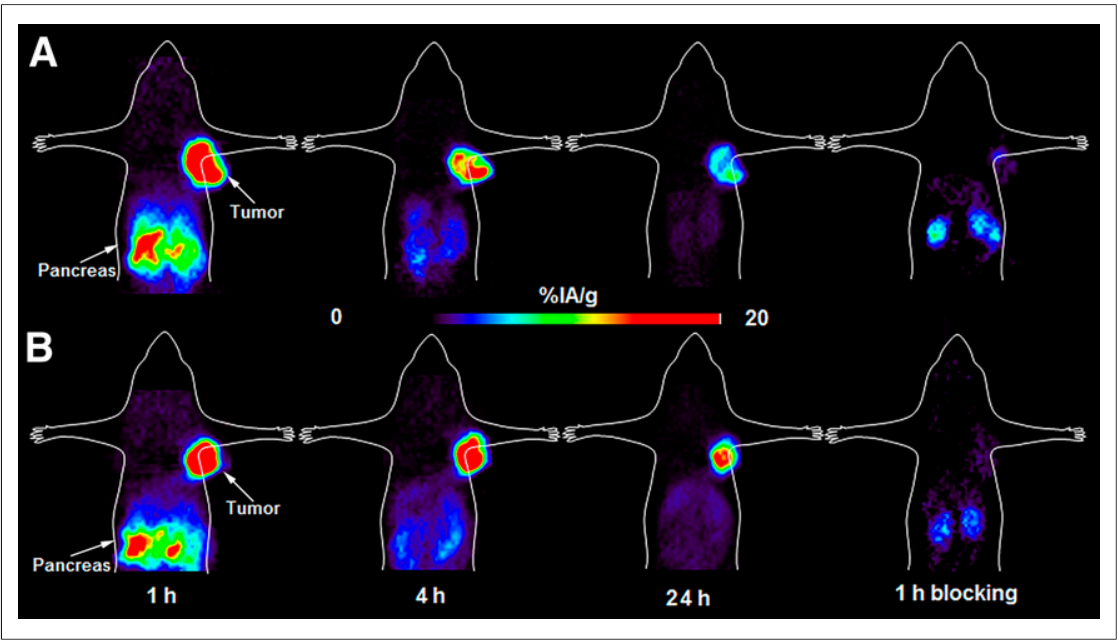

FIGURE 5. PET imaging of PC3 tumor-bearing mice on injection of ${ }^{64} \mathrm{Cu}-\mathrm{NODAGA}-\mathrm{MJ9}(\mathrm{A})$ and ${ }^{64} \mathrm{Cu}-\mathrm{NOTA}-\mathrm{MJ9}$ (B) at 1,4 , and $24 \mathrm{~h}$ after injection along with blocking studies at $1 \mathrm{~h}$ after injection. Tumor and pancreas are indicated with arrows.
NOTA-MJ9 and NODAGA-MJ9 were labeled with ${ }^{68} \mathrm{Ga}$ and ${ }^{64} \mathrm{Cu}$. Because of its availability from generator systems, the positron emitter ${ }^{68} \mathrm{Ga}$ has gained rapidly increasing interest in the field of radiopharmaceutical chemistry (38). On the other hand, ${ }^{64} \mathrm{Cu}$ is a positron emitter with a longer half-life $(12.7 \mathrm{~h})$ than ${ }^{68} \mathrm{Ga}$ (67.8 min) and can give real-time PET images of the physiologic processes at later time points with improved tumor-to-background ratios (39). ${ }^{64} \mathrm{Cu}$ radiopharmaceuticals can be produced centrally and shipped to distant hospitals. Both MJ9 conjugates were labeled with ${ }^{68} \mathrm{Ga}$ and ${ }^{64} \mathrm{Cu}$ with high labeling yields at high specific activities. ${ }^{68} \mathrm{Ga}$-NODAGA-MJ9 exhibits 2-foldhigher specific activity than ${ }^{68}$ Ga-NOTA-MJ9. The third available carboxymethyl group of NODAGA facilitates the incorporation of $68 / \mathrm{nat} \mathrm{Ga}$, compared with NOTA, where one of the carboxymethyl groups is involved in the coupling with the spacer, rendering the introduction of the radiometal more difficult, and high temperatures are needed to achieve efficient labeling.

${ }^{68} \mathrm{Ga}-\mathrm{NOTA}$ - and ${ }^{68} \mathrm{Ga}-\mathrm{NODAGA}-\mathrm{MJ} 9$ are taken up by the GRPr-positive organs in PC3 tumor-bearing mice at early time points by a receptor-mediated process as shown by the blocking studies. The pancreas was the organ with the highest accumulated activity, followed by the tumor, which also showed remarkably high uptake. Compared with ${ }^{68} \mathrm{Ga}-\mathrm{RM} 2$ reported by Mansi et al., the uptake in the pancreas was more than 2-fold-higher at 1 and $2 \mathrm{~h}$ after injection whereas the tumor uptake for ${ }^{68} \mathrm{Ga}$-NODAGAMJ9 was 1.2- and 1.5- and for ${ }^{68} \mathrm{Ga}-\mathrm{NOTA}-\mathrm{MJ} 9$ 1.65- and 1.45 fold-higher at the same time points (9). NOTA-PEG 2 was coupled to the same GRPr antagonist by Varasteh et al. and labeled with ${ }^{68} \mathrm{Ga}(32)$. The biodistribution studies at $1 \mathrm{~h}$ after injection showed lower pancreas and tumor uptake by a factor of about 10 and 2 , respectively, than ${ }^{68} \mathrm{Ga}-\mathrm{NOTA}-\mathrm{MJ} 9$. We assume that this is the consequence of the improved binding affinities of the metalloMJ9 conjugates.

However, the acquisition of PET images at later time points with the ${ }^{64} \mathrm{Cu}$-labeled conjugates allowed a more comprehensive monitoring of their in vivo performance. ${ }^{64} \mathrm{Cu}-\mathrm{NOTA}-$ and ${ }^{64} \mathrm{Cu}-$ NODAGA-MJ9 are specifically taken up by the GRPr-positive organs such as the tumors and the pancreas at early time points, but they were washed out at a rate different from these tissues. The quantitative analysis of the PET images (Fig. 6) showed that the pancreas uptake was at the same or even higher level in the case of ${ }^{64} \mathrm{Cu}-\mathrm{NODAGA}-\mathrm{MJ} 9$ than the tumor uptake at $1 \mathrm{~h}$ after injection. Already at $4 \mathrm{~h}$ after injection, the activity in the abdomen was cleared whereas the tumor uptake still remained high, leading to PET images of high contrast. The peptide with the higher affinity, ${ }^{64} \mathrm{Cu}$-NOTAMJ9, also showed the longer retention time (Fig. 5).

Different retention times of the tracers in the tumor and pancreas have also been observed for other GRPr antagonists already studied $(8-10,29,30)$, but this was not the case for GRPr agonists (16) for which pancreas uptake was found to be high over time. Recently, Liu et al. (31) have coupled NODAGA to RM1 (antagonist) and to AMBA (agonist) and labeled 


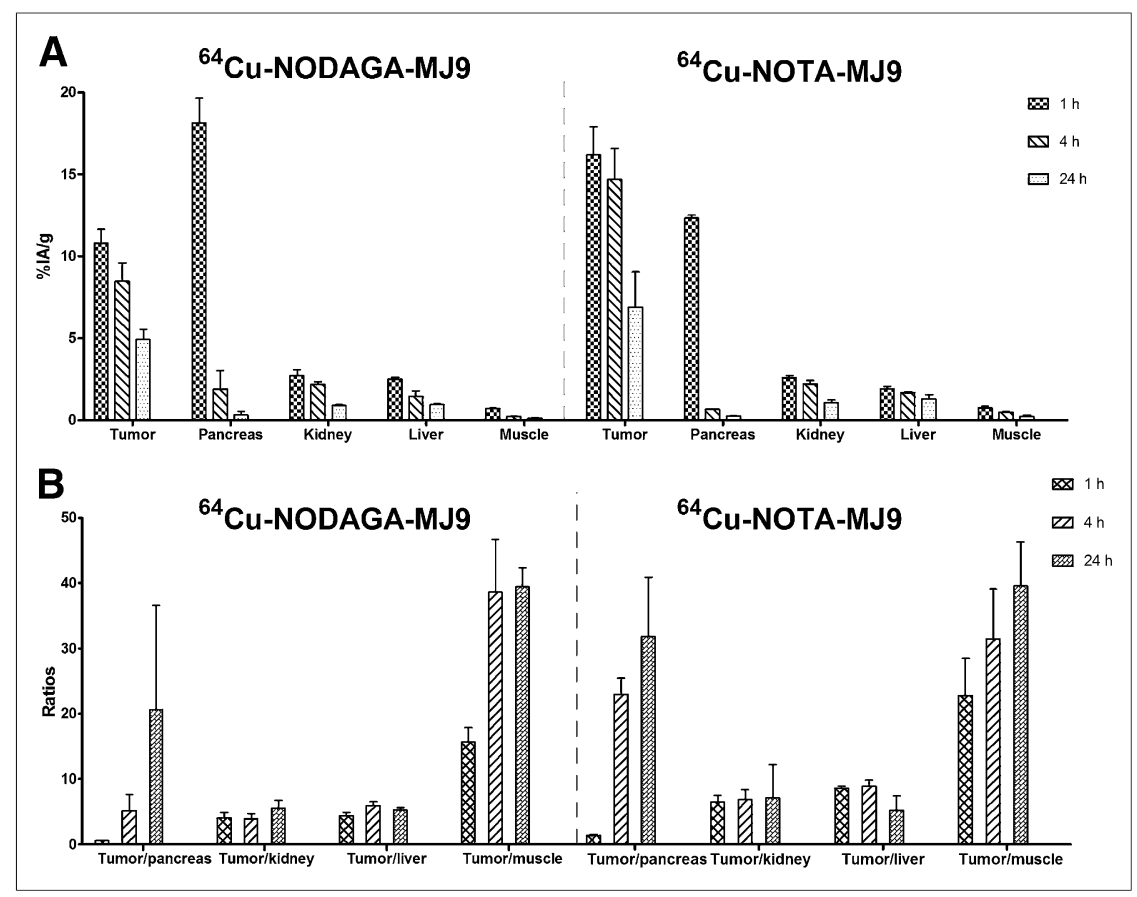

FIGURE 6. Quantitative analysis of PET images of ${ }^{64} \mathrm{Cu}-\mathrm{NODAGA}-\mathrm{MJ9}$ and ${ }^{64} \mathrm{Cu}$-NOTA-MJ9: $\% \mathrm{IA} / \mathrm{g}(\mathrm{A})$ and tumor-to-background ratios $(\mathrm{B})$.

\section{CONCLUSION}

We have demonstrated that NOTA (coupled as monoamide) and NODAGA can be coupled to a statine-based GRPr antagonist, leading to an improvement in regard to the GRPr affinity, compared with the native $\mathrm{BN}$. The NODAGA conjugate showed advantages regarding labeling at room temperature and superior specific activity, compared with the NOTA derivative. Both ${ }^{68} \mathrm{Ga}$ - and ${ }^{64} \mathrm{Cu}$-labeled conjugates were taken up specifically by the tumor and the GRPr-positive organs at early time points, but the longer half-life of ${ }^{64} \mathrm{Cu}$ allowed improved tumor-to-background ratios at later time points.

The promising in vivo pharmacokinetic performance of the new radiopeptides may contribute to the improvement of the diagnostic imaging of tumors overexpressing GRPr. ${ }^{68} \mathrm{Ga}$-NODAGA-MJ9 is currently being studied in a phase I study in one of our laboratories. the 2 conjugates with ${ }^{64} \mathrm{Cu}$ and ${ }^{18} \mathrm{~F}-\mathrm{AlF}$. They found low but specific tumor uptake for both the antagonist and the agonist, but the former showed significantly lower abdominal uptake. They concluded that the antagonist revealed a better performance and higher tumor uptake despite the distinctly higher affinity of the agonist. In addition, the clearance from the tumor is more rapid for the agonists despite their known ability to internalize on receptor binding. The authors concluded that ${ }^{18} \mathrm{~F}-\mathrm{AlF}-$ NODAGA-RM1 has great potential for clinical translation. The reason for the differences in retention time is not fully understood yet. It may be due to species differences (human origin in PC3 tumors vs. murine origin in the pancreas) or to a more efficient perfusion of the pancreas than the tumor. In our first clinical study using ${ }^{64} \mathrm{Cu}$-(4,11-bis(carboxy-methyl)-1,4,8,11tetraazabicyclo(6.2.2)hexadecane)-PEG 4 -D-Phe-Gln-Trp-AlaVal-Gly-His-Sta-Leu- $\mathrm{NH}_{2}$, we found similar pharmacokinetics with regard to tumor-to-pancreas ratios. Radioactivity cleared much faster from the pancreas than from the tumor between 4 and $20 \mathrm{~h}$, increasing the ratio from about 2 at $4 \mathrm{~h}$ to more than 10 at $20 \mathrm{~h}$. In addition, the clearance from other organs was also faster than from the tumor (11). These pharmacokinetic data are promising and suggest that this strategy may also lead to targeted radionuclide therapy with ${ }^{67} \mathrm{Cu}$, potentially providing a promising theranostic pair.

${ }^{64} \mathrm{Cu}$-NOTA was coupled before via an 8 -aminooctanoic acid spacer to the agonist $\mathrm{BN}(7-14) \mathrm{NH}_{2}$ (40). The authors found high GRPr affinity, but more important they reported low liver uptake and therefore concluded that the radiocopper peptide is stable in vivo. No demetallation was found in the PC3 tumor xenografts, contrary to conjugates with DOTA or 1,4,8,11-tetraazacyclotetradecane1,4,8,11-tetraacetic acid (TETA). The in vivo stability of the ${ }^{64} \mathrm{Cu}-$ labeled MJ9 GRPr antagonists was also demonstrated by their low hepatic accumulation, indicating their high resistance to transchelation of ${ }^{64} \mathrm{Cu}$ (II) to proteins, showing highly promising preclinical data.

\section{DISCLOSURE}

The costs of publication of this article were defrayed in part by the payment of page charges. Therefore, and solely to indicate this fact, this article is hereby marked "advertisement" in accordance with 18 USC section 1734. This work was supported by the German Consortium for Translational Cancer Research (DKTK). No other potential conflict of interest relevant to this article was reported.

\section{ACKNOWLEDGMENTS}

We thank Yvonne Kiefer and Roswitha Toennesmann for their technical assistance.

\section{REFERENCES}

1. Lee S, Xie J, Chen X. Peptides and peptide hormones for molecular imaging and diseases diagnosis. Chem Rev. 2010;110:3087-3111.

2. Reubi JC. Peptide receptors as molecular targets for cancer diagnosis and therapy. Endocr Rev. 2003;24:389-427.

3. Schroeder RPJ, van Weeden WM, Bangma C, Krenning EP, de Jong M. Peptide receptor imaging of prostate cancer with radiolabeled bombesin analogues. Methods. 2009;48:200-204.

4. Bodei L, Ferrari M, Nunn AD, et al. ${ }^{177}$ Lu-AMBA bombesin analogue in hormone refractory prostate cancer patients: a phase I escalation study with single-cycle administrations [abstract]. Eur J Nucl Med Mol Imaging. 2007;34(suppl 2):S221.

5. Casanueva FF, Perez FR, Casabiell X, Camina JP, Cai RZ, Schally AV. Correlation between the effects of bombesin antagonists on cell proliferation and intracellular calcium concentration in Swiss 3T3 and HT-29 cell lines. Proc Natl Acad Sci USA. 1996;93:1406-1411.

6. Ginj M, Zhang H, Waser B, et al. Radiolabeled somatostatin receptor antagonists are preferable to agonists for in vivo peptide receptor targeting of tumors. Proc Natl Acad Sci USA. 2006;103:16436-16441.

7. Cescato R, Maina T, Nock B, et al. Bombesin receptor antagoists may be preferable to agonists for tumor targeting. J Nucl Med. 2008;49:318-326.

8. Mansi R, Wang X, Forrer F, et al. Evaluation of a 1,4,7,10-tetraazacyclododecane1,4,7,10-tetraacetic acid-conjugated bombesin-based radioantagonist for the labeling with single-photon emission computed tomography, positron emission 
tomography, and therapeutic radionuclides. Clin Cancer Res. 2009;15: 5240-5249.

9. Mansi R, Wang X, Forrer F, et al. Development of a potent DOTA-conjugated bombesin antagonist for targeting GRP-r-positive tumors. Eur J Nucl Med Mol Imaging. 2011;38:97-107.

10. Abiraj K, Mansi R, Tamma ML, et al. Bombesin antagonist-based radioligands for translational nuclear imaging of gastrin-releasing peptide receptor-positive tumors. J Nucl Med. 2011;52:1970-1978.

11. Wieser G, Mansi R, Grosu AL, et al. Positron emission tomography (PET) imaging of prostate cancer with a gastrin releasing peptide receptor antagonist - from mice to men. Theranostics. 2014;4:412-419.

12. Llinares M, Devin C, Chaloin O, et al. Synthesis and biological activities of potent bombesin receptor antagonists. J Pept Res. 1999;53:275-283.

13. Atherton E. Fluorenylmethoxycarbonyl-Polyamide Solid Phase Peptide Synthesis: General Principles and Development. Oxford, U.K.: Oxford Information Press; 1989:25-38.

14. Markwalder R, Reubi JC. Gastrin-releasing peptides receptors in the human prostate: relation to neoplastic transformation. Cancer Res. 1999;59:1152-1159.

15. Mansi R, Fleischmann A, Maecke HR, Reubi JC. Targeting GRPR in urological cancers-from basic research to clinical application. Nat Rev Urol. 2013;10:235-244.

16. Zhang H, Abiraj K, Thorek DLJ, et al. Evolution of bombesin conjugates for targeted PET imaging of tumors. PLOS ONE. 2012;7:e44046.

17. Zhang H, Chen J, Waldherr C, et al. Synthesis and evaluation of bombesin derivatives on the basis of pan-bombesin peptides labeled with indium-111, lutetium-177, and yttrium-90 for targeting bombesin receptor-expressing tumors. Cancer Res. 2004;64:6707-6715.

18. Nock BA, Nikolopoulou A, Galanis A, et al. Potent bombesin-like peptides for GRP receptor targeting of tumors with ${ }^{99 \mathrm{~m}} \mathrm{Tc}$ : a preclinical study. J Med Chem. 2005;48:100-110.

19. Bergmann R, Ruffani A, Graham B, et al. Synthesis and radiopharmacological evaluation of ${ }^{64} \mathrm{Cu}$-labeled bombesin analogs featuring a bis(2-pyridylmethyl)1,4,7-triazacyclononane chelator. Eur J Med Chem. 2013;70:434-446.

20. Yang Y-S, Zhang X, Xiong Z, Chen X. Comparative in vitro and in vivo evaluation of two ${ }^{64} \mathrm{Cu}$-labeled bombesin analogs in a mouse model of human prostate adenocarcinoma. Nucl Med Biol. 2006;33:371-380.

21. Dijkgraaf I, Franssen GM, McBride WJ, et al. PET of tumors expressing gastrinreleasing peptide receptor with an ${ }^{18} \mathrm{~F}$-labeled bombesin analog. J Nucl Med. 2012;53:947-952.

22. Liu Z, Li Z-B, Cao Q, Liu S, Wang F, Chen X. Small-animal PET of tumors with ${ }^{64} \mathrm{Cu}$-labeled RGD-bombesin heterodimer. J Nucl Med. 2009;50:1168-1177.

23. Zhou Z, Wagh NK, Ogbomo SM, et al. Synthesis and in vitro and in vivo evaluation of hypoxia-enhanced ${ }^{111}$ In-bombesin conjugates for prostate cancer imaging. J Nucl Med. 2013;54:1605-1612.

24. Durkan K, Zongrum J, Rold TL, et al. A heterodimeric [RGD-Glu[ $\left.{ }^{64} \mathrm{Cu}-\mathrm{NO} 2 \mathrm{~A}\right]-$ 6-Ahx-RM2] $\alpha_{\mathrm{v}} \beta_{3} /$ GRPr-targeting antagonist radiotracer for PET imaging of prostate tumors. Nucl Med Biol. 2014;41:133-139.
25. Jackson AB, Nanda PK, Rold TL, et al. ${ }^{64} \mathrm{Cu}-\mathrm{NO} 2 \mathrm{~A}-\mathrm{RGD}-\mathrm{Glu}-6-\mathrm{Ahx}-\mathrm{BBN}(7-$ 14)NH2: a heterodimeric targeting vector for positron emission tomography imaging of prostate cancer. Nucl Med Biol. 2012;39:377-387.

26. Fani M, Del Pozzo L, Abiraj K, et al. PET of somatostatin receptor-positive tumors using ${ }^{64} \mathrm{Cu}$ - and ${ }^{68} \mathrm{Ga}$-somatostatin antagonists: the chelate makes the difference. J Nucl Med. 2011;52:1110-1118.

27. Wadas TJ, Eiblmaier M, Zheleznyak A, et al. Preparation and biological evaluation of ${ }^{64} \mathrm{Cu}-\mathrm{CB}-\mathrm{TE} 2 \mathrm{~A}-\mathrm{sst} 2-\mathrm{ANT}$, a somatostatin antagonist for PET imaging of somatostatin receptor-positive tumors. J Nucl Med. 2008;49:1819-1827.

28. Wild D, Fani M, Behe M, et al. First clinical evidence that imaging with somatostatin receptor antagonists is feasible. J Nucl Med. 2011;52:1412-1417.

29. Abd-Elgaliel WR, Gallazzi F, Garrison JC, et al. Design, synthesis and biological evaluation of an antagonist-bombesin analogue as targeting vector. Bioconjug Chem. 2008;19:2040-2048.

30. Marsouvanidis PJ, Nock BA, Hajjaj B, et al. Gastrin releasing peptide receptordirected radioligands based on a bombesin antagonist: synthesis, ${ }^{111} \mathrm{In}$-labeling, and preclinical profile. J Med Chem. 2013;56:2374-2384.

31. Liu Y, Hu X, Liu H, et al. A comparative study of radiolabeled bombesin analogs for the PET imaging of prostate cancer. J Nucl Med. 2013;54:2132-2138.

32. Varasteh Z, Velikyan I, Lindeberg G, et al. Synthesis and characterization of a high-affinity NOTA-conjugate bombesin antagonist for GRPR-targeted tumor imaging. Bioconjug Chem. 2013;24:1144-1153.

33. Yang M, Gao H, Zhou Y, et al. ${ }^{18} \mathrm{~F}-$ labeled agonists and antagonists: a comparative study in prostate cancer imaging. Theranostics. 2011;1:220-229.

34. Nanda PK, Wienhoff BE, Rold TL, et al. Positron-emission tomography (PET) imaging agents for diagnosis of human prostate cancer: agonist vs. antagonist ligands. In Vivo. 2012;26:583-592.

35. Roivainen A, Kähkönen E, Luoto P, et al. Plasma pharmacokinetics, whole-body distribution, metabolism, and radiation dosimetry of ${ }^{68} \mathrm{Ga}$ bombesin antagonist BAY 86-7548 in healthy men. J Nucl Med. 2013;54:867-872.

36. Kähkönen E, Jambor I, Kemppainen J, et al. In vivo imaging of prostate cancer using $\left[{ }^{68} \mathrm{Ga}\right]$-labeled bombesin analog BAY68-7548. Clin Cancer Res. 2013; 19:5434-5443.

37. Lears KA, Ferdani R, Liang K, et al. In vitro and in vivo evaluation of ${ }^{64} \mathrm{Cu}-$ labeled SarAr-bombesin analogs in gastrin-releasing peptide receptor-expressing prostate cancer. J Nucl Med. 2011;52:470-477.

38. Roesch F, Riss PJ. The renaissance of the ${ }^{68} \mathrm{Ge} /{ }^{68} \mathrm{Ga}$ radionuclide generator initiates new developments in ${ }^{68} \mathrm{Ga}$ radiopharmaceutical chemistry. Curr Top Med Chem. 2010;10:1633-1668.

39. Anderson CJ, Ferdani R. Copper-64 radiopharmaceuticals for PET imaging of cancer: advances in preclinical and clinical research. Cancer Biother Radiopharm. 2009;24:379-393.

40. Prasanphanich AF, Nanda PK, Rold TL, et al. $\left[{ }^{64} \mathrm{Cu}-\mathrm{NOTA}-8-A o c-B B N(7-14)\right.$ $\mathrm{NH}_{2}$ ] targeting vector for positron-emission tomography imaging of gastrinreleasing peptide receptor-expressing tissues. Proc Natl Acad Sci USA. 2007; 104:12462-12467. 